Original Research Article

\title{
Drug utilization pattern of antimicrobials use in upper respiratory tract infection in paediatric patient of rural tertiary care hospital
}

\author{
Varsha P. Gajbhiye ${ }^{1 *}$, Lamture Y. R. ${ }^{2}$
}

${ }^{1}$ Department of Pharmacology, ${ }^{2}$ Department of Surgery, J.N. Medical College, Wardha, Maharashtra, India

Received: 01 October 2018

Revised: 27 October 2018

Accepted: 01 November 2018

*Correspondence to:

Dr. Varsha P. Gajbhiye,

Email: dryrlamture@

yahoo.co.in

Copyright: (C) the author(s), publisher and licensee Medip Academy. This is an openaccess article distributed under the terms of the Creative Commons Attribution NonCommercial License, which permits unrestricted noncommercial use, distribution, and reproduction in any medium, provided the original work is properly cited.

\begin{abstract}
Background: Antimicrobial agents (AMAs) are most commonly prescribed drugs for lower respiratory tract infection (LRTI). This study was conducted to evaluate pattern of prescription and AMAs use in paediatric patient for LRTI in wards of rural tertiary care teaching hospital.

Methods: This is prospective, observational study undertaken in paediatric patient in tertiary care hospital. Prescriptions of 60 patient of age group 1-12years diagnosed with LRTI admitted in paediatric ward of rural tertiary care teaching hospital were studied. Positive blood sample were studied for common microorganisms, their sensitivity and resistance to AMAs.

Results: Out of 60 patients admitted in paediatric ward of LRTI, 12 patients were of mild to moderate pneumonia, three patients were of bronchiolitis, ten patients were of croups, three patients were of bronchitis and 37 patients were of severe pneumonia. The most frequently prescribed AMAs were combination of cephalosporin and aminoglycosides. The most common organism isolated was streptococcus pneumoniae sensitive to vancomycin in $92.3 \%$ and meropenem in $84.6 \%$, resistant to ampicillin, amoxicillin and cloxacillin in $92.3 \%$ of cases.

Conclusions: The study shows utilisation pattern of AMAs in LRTI, prescribing on which future intervention studies may be based to promote rational drug use.
\end{abstract}

Keywords: Antimicrobial, Infection, Sensitivity

\section{INTRODUCTION}

Lower Respiratory Tract Infection (LRTI) is frequently associated with significant morbidity and mortality in children. ${ }^{1}$ LRTI is defined as any infection that affects the airways below the epiglottis and includes acute laryngitis, tracheitis, croup, bronchitis and bronchiolitis, and lung infections such as pneumonia, tuberculosis and empyema. ${ }^{2}$

World health organisation (WHO) estimated burden of respiratory tract infections in 2010, estimates four and half million deaths due to respiratory tract infections among children every year. In India, 1.2 million deaths have been reported among children due to LRTI among 5.9 million deaths globally. India has the highest number of deaths among children $<5$ years of age and most of them are due to respiratory tract infections. ${ }^{3}$

Lower respiratory tract infections are most common causes of death than upper respiratory tract infections. Pneumonia is most common types of LRTI in children. Both bacteria and viruses can cause pneumonia. Bacterial pneumonia is often caused by Streptococcus pneumoniae (pneumococcal) or Haemophilus influenza, mostly type b(Hib), and occasionally by Staphylococcus aureus or other Streptococci. Other pathogens, such as Mycoplasma pneumoniae and Chlamydia pneumoniae, cause atypical pneumonias. Their role as a cause of severe disease in children under five in developing countries is unclear. ${ }^{4}$ The early detection and management with appropriate 
antimicrobial are essential to maintain the long-term respiratory and overall health of children. ${ }^{5}$

LRTIs are major reason for AMAs utilisation and changes in AMAs resistance patterns are threat to its effective treatment, hence there is increasing concern about AMAs prescription in community. ${ }^{6}$ Antibiotic utilization is much greater in most of the areas of the world and has been implicated in the development of antimicrobial-resistant strains. Antibiotics are regarded as being overprescribed for pediatric respiratory infections, contributing to the problem of antibiotic resistance. ${ }^{7}$

The aim of present study was to focus on trends in AMAs utilisation, common microorganism isolated from blood culture, sensitivity and resistance pattern in LRTIs in children admitted in paediatric ward in rural area.

\section{METHODS}

Type of the present study is prospective, observational study and the study conducted at Mahatma Gandhi Institute of Medical Sciences, Sevagram. The sample size is 60 patients admitted in paediatric ward. This study was approved by the institute ethics committee of our hospital and informed consent was obtained before it. This study was carried out by collecting prescription of patient admitted in paediatric ward of rural tertiary care teaching hospital between period of $1^{\text {st }}$ March 2018 till $24^{\text {th }}$ September 2018.The patient's demographic data, clinical history, family history, immunization coverage, house hold contacts history, type of delivery and a thorough clinical examination was done and signs and symptoms were recorded in a separate predesigned questionnaire sheet. Out of total admission of 200 patient in paediatric ward during this period, 60 patients were diagnosed as LRTI and were selected for study. Patient of age range 112 years, clinically diagnosed as LRTI, who did not receive any AMAs within 24 hours of admission were included. Patient discharged against medical advice were excluded from study. Blood samples for culture and sensitivity pattern were sent in those patients who were clinically distressed. Common microorganisms found in positive blood sample, their sensitivity and resistance to AMAs were recorded. Mantoux test was done in suspected cases of tuberculosis. All the cases were followed regularly on admission observed for improvement or detoriation.

\section{Inclusion criteria}

- Patient of age range 1-12years

- Clinically diagnosed as LRTI by paediatrician

- Who did not receive any AMAs within 24 hours of admission.

\section{Exclusion criteria}

- $\quad$ Than 1year

- $\quad>$ than 12 years
- Received any AMAs within 24 hours of admission

- Child with congenital heart disease and lung disorder

\section{Statistical analysis}

The data collected were subjected to descriptive statistical analysis using Microsoft Excel. All the variables were entered and analyzed by Graph pad prism software.

\section{RESULTS}

A total number of patients in study were 60 . Out of total 60 patient, 40 were male and 20 were female. This figure shows the number of females were less when compared with male. This figures also shows significant increase in admission of males of LRTIs as compared to male (Figure 1).

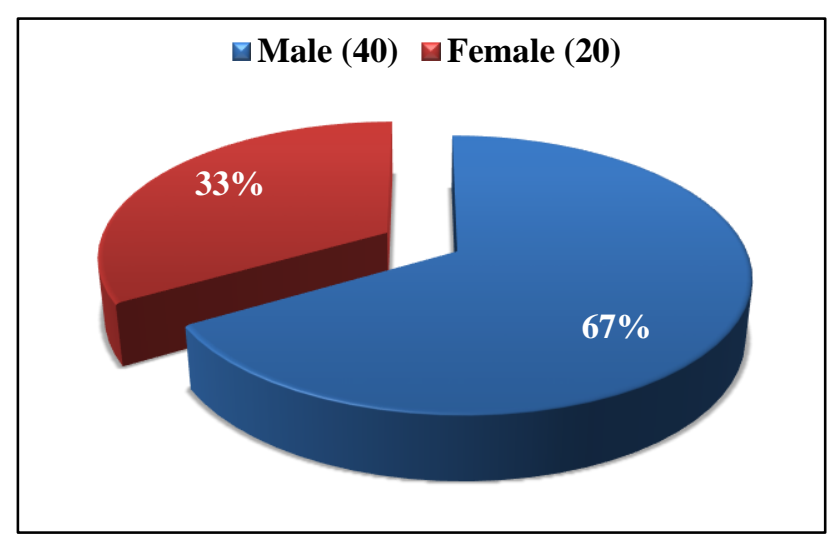

Figure 1: Gender in study group.

Most common sign of LRTI was not feeding well in $96.6 \%$ of cases followed by fever and cough in $93.3 \%$. Breathlessness was seen in $81.6 \%$ and in drawing of chest seen in $61.66 \%$. Indrawing of intercostals space and breathlessness is common sign in severe pneumonia (Table 1).

Table 1: Sign and symptoms of LRTI in cases of the study.

\begin{tabular}{|lll|}
\hline Symptoms & $\begin{array}{l}\text { Number } \\
(\mathbf{n = 6 0})\end{array}$ & $\%$ \\
\hline Fever & 56 & $93.3 \%$ \\
\hline Cough & 56 & $93.3 \%$ \\
\hline Breathlessness & 49 & $81.6 \%$ \\
\hline Indrawing of intercostal space & 37 & $61.66 \%$ \\
\hline Not taking feed & 58 & $96.66 \%$ \\
\hline
\end{tabular}

Out of 60 patients of LRTI, AMAs prescribed for 12 patients of mild-moderate pneumonia was combination of amoxicillin and clavulanate. 3 patients of bronchiolitis were prescribed ceftriaxone. 5 patients of croup were prescribed amoxicillin. 3 patients of bronchitis were prescribed bronchitis. 37 patients were diagnosed as severe 
pneumonia and prescribed AMAs were combination of ceftriaxone and amikacin.

Table 2: Prescriptions of AMAs in LRTI $(n=60)$.

\begin{tabular}{|lll|}
\hline Diagnosis & $\begin{array}{l}\text { Total no. of } \\
\text { patients }\end{array}$ & $\begin{array}{l}\text { Common AMAs } \\
\text { prescribed }\end{array}$ \\
\hline $\begin{array}{l}\text { Mild-moderate } \\
\text { pneumonia }\end{array}$ & 12 & $\begin{array}{l}\text { Amoxicillin and } \\
\text { clavulanate }\end{array}$ \\
\hline Bronchiolitis & 3 & Ceftriaxone \\
\hline Croup & 5 & Amoxicillin \\
\hline Bronchitis & 3 & Cefixime \\
\hline $\begin{array}{l}\text { Severe } \\
\text { pneumonia }\end{array}$ & 37 & $\begin{array}{l}\text { Ceftriaxone } \\
\text { +amikacin }\end{array}$ \\
\hline
\end{tabular}

Croup and bronchitis were prescribed oral route of AMA administration whereas severe pneumonia, mild-moderate pneumonia, bronchiolitis was prescribed with parenteral route which is considered to be life threatening disease. Combined AMAs were prescribed in severe and mildmoderate pneumonia whereas monotherapy (AMA) was prescribed for bronchiolitis, bronchitis and croup (Table 2).

Out of 60 patients, blood samples were sent for culture and sensitivity in 49 patients diagnosed with mild to moderate and severe pneumonia. Of these 49 patients, 31 samples were positive for culture report. Of 31 positive blood culture, the most common microorganism was Streptococcus pneumoniae in $13(40.9 \%)$, followed by Pseudomonas aeruginosa in 6 (19.35\%), Klebsiella pneumoniae in $5(16.12 \%)$. Least common microorganism was coagulase negative Staphylococcus found in $2(6.45 \%)$ and Acinetobacter found in 1 (3.22\%) sample (Figure 2).

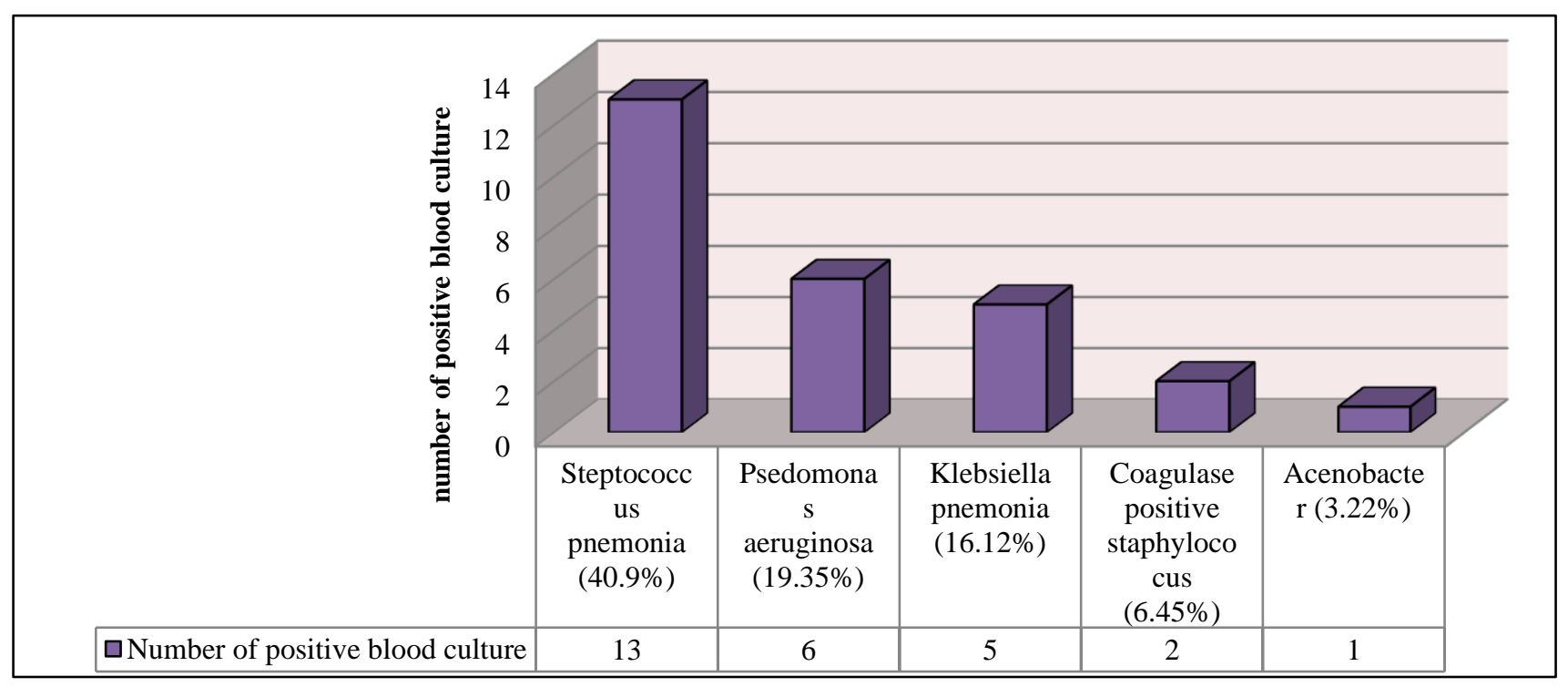

Figure 2: Microorganism found in positive culture sample $(n=31)$.

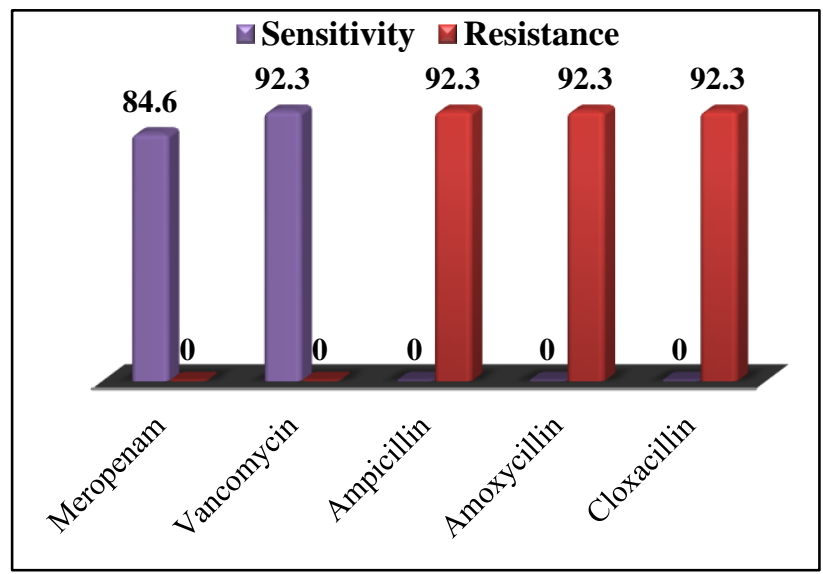

Figure 3: Sensitivity pattern for Streptococcus pneumoniae.
In sensitivity pattern, it was observed that Streptococcus pneumoniae; the most common microorganism was sensitive to meropenem in $84.6 \%$, vancomycin in $92.3 \%$, resistant to ampicillin, amoxicillin and cloxacillin in 92.3\%. Overall the graph shows, that most common microorganism is streptococcus pneumoniae and most commonly sensitive to vancomycin (Figure 3).

\section{DISCUSSION}

This study showed predominance of male children over female (Figure 1) as was also seen in study done by Palikhe N. ${ }^{8}$ This can be attributable to prevalence of gender inequality as a result of which males are preferentially taken to tertiary care unit for treatment as compared to females with similar severity of illness. 
In this study, among LRTIs, pneumonia (Table 2) was most common cause for admission. Common sign and symptom (Table 1) were not taking feed $(96.6 \%)$ fever and cough $(93.3 \%)$ and breathlessness $(96.6 \%)$. This could be explained by the fact that admission in wards was more of patient of pneumonia. A study done by Abramczyk et al, has similar. ${ }^{9}$

Prescribing pattern of AMAs in this study shows that combined AMAs were prescribed for pneumonia. These combined AMAs were combination of cephalosporin and aminoglycosides. This pattern of prescription was similar to study done by Ilia et al. ${ }^{10}$

Results pertaining to microbiological profiles show that streptococcus pneumonia (Figure 2) is more common organism. Streptococcus pneumoniae is the leading cause of community acquired pneumonia (CAP) as shown in study done by File TM Jr et al. ${ }^{11}$

Streptococcus pneumoniae was sensitive (Figure 3) to meropenem in $84.6 \%$ and vancomycin in $92.3 \%$ and resistant to ampicillin in $92.3 \%$, amoxicillin in $92.3 \%$ and cloxacillin in $92.3 \%$. These results are similar as those mentioned by Hachiya et al. ${ }^{12}$ In this study; parenteral route was more common than the oral route. This is clarified by explanation that patients admitted were in critically ill condition and most commonly prescribed AMAs were in a combination of cephalosporin and aminoglycosides and ceftriaxone which is available in parenteral form.

AMAs are most commonly prescribed drugs in LRTIs, thus special measures are imperative for their rational usage to prevent the emergence of resistance. This preliminary study has given an insight into pattern of AMAs prescribing on which future intervention studies may be based to promote rational drug use.

\section{ACKNOWLEDGEMENTS}

Authors would like to acknowledge pharmacology department and central laboratory for kind co-operation to complete this work.

Funding: No funding sources Conflict of interest: None declared

Ethical approval: The study was approved by the Institutional Ethics Committee

\section{REFERENCES}

1. Chang AB, Chang CC, O'Grady K, Torzillo PJ. Lower respiratory tract infections. Pediatr Clin. 2009 Dec $1 ; 56(6): 1303-21$.
2. Lanata CF, Rudan I, Boschi-Pinto C, Tomaskovic L, Cherian T, Weber M, et al. Methodological and quality issues in epidemiological studies of acute lower respiratory infections in children in developing countries. Int J Epidemiol. 2004 May 27;33(6):136272.

3. Bradley JS, Byington CL, Shah SS, Alverson B, Carter ER, Harrison C, et al. The management of communityacquired pneumonia in infants and children older than 3 months of age: clinical practice guidelines by the Pediatric Infectious Diseases Society and the Infectious Diseases Society of America. Clin Infectious Dis. 2011 Oct 1;53(7):e25-76.

4. Francis BV, Abhilash TG. Study of acute respiratory tract infections in children. Int J Sci Res. 2016; 5(9):1791-2.

5. Grant CC, Scragg R, Tan D, Pati A, Aickin R, Yee RL. Hospitalisation for pneumonia in children in Auckland, New Zealand. J Paediatr Child Health. 1998 Aug;34(4):355-9.

6. Wattal C, Goel N, Oberoi JK, Raveendran R, Datta S, Prasad KJ. Surveillance of multidrug resistant organisms in tertiary care hospital in Delhi, India. J Assoc Physicians India. 2010 Dec;58(Suppl):32-6.

7. Sachdeva PD, Patel BG. Drug utilization studiesscope and future perspectives. Int J Pharmaceut Biol Res. 2010;1(1):11-7.

8. Palikhe N. Prescribing pattern of antibiotics in pediatric hospital of Kathmandu valley. J Nepal Health Res Council. 2004 Jan; 2(2):31-6.

9. Abramczyk ML, Carvalho WB, Carvalho ES, Medeiros EA. Nosocomial infection in a pediatric intensive care unit in a developing country. Brazilian J Infectious Dis. 2003 Dec;7(6):375-80.

10. Ilia S, Spanaki AM, Geromarkaki E, Filippou O, Briassouli E, Fitrolaki DM, et al. Contribution to mortality and resource usage of nosocomial and community infections in an intensive care setting. Arch Int J Med. 2009 Oct 1;2(4).

11. File Jr TM. Streptococcus pneumoniae and community-acquired pneumonia: a cause for concern. Am J Med Supplements. 2004 Aug 2;117(3):39-50.

12. Gajbhiye V, Kale R, Vilhekar K, Bahekar S. Drug utilization study on antimicrobials use in lower respiratory tract infection in Pediatric Intensive Care Unit of Rural Tertiary Care Hospital. J Med Society. 2016 Sep 1;30(3):146.

Cite this article as: Gajbhiye VP, Lamture YR. Drug utilization pattern of antimicrobials use in upper respiratory tract infection in paediatric patient of rural tertiary care hospital. Int J Basic Clin Pharmacol 2019;8:74-7. 